\title{
FORMAÇÃO DE PROFESSORES NOS DEBATES \\ DA I CONFERÊNCIA NACIONAL DE EDUCAÇÃO (ICNE - 1927)
}

\author{
VIEIRA, Carlos Eduardo (Brasil, Paraná, Curitiba) ${ }^{1 *}$; \\ FARIA, Maria Cristiane Nunes de (Brasil, Paraná, Curitiba) ${ }^{1 * *}$ \\ 1 Universidade Federal do Paraná \\ https://orcid.org/0000-0001-6168-271X \\ https://orcid.org/0000-0002-6039-270X
}

\section{RESUMO}

Este artigo busca analisar os sentidos associados às discussões sobre os processos de formação de professores no contexto da I Conferência Nacional de Educação promovida pela Associação Brasileira de Educação. Essa conferência representou o início de uma sequência de encontros nacionais da referida associação que delinearam um campo de disputas políticas, teóricas e institucionais. Este evento, ocorrido em 1927, teve como tema o ensino
\end{abstract} primário e gerou uma expressiva documentação, com destaque para as 113 teses apresentadas. Estas e outros documentos da Associação Brasileira de Educação compõem as fontes que sustentam esta análise, que busca identificar conceitos normativos e antitéticos assimétricos presentes no jogo de linguagem que estruturou os debates na I Conferência Nacional de Educação. A análise dessa linguagem possibilitou a compreensão do lugar e do significado do professor no discurso abeano.

PALAVRAS-CHAVE: I Conferência Nacional de Educação. Associação Brasileira de Educação. Formação de professores. Conceitos antitéticos assimétricos. Jogo de linguagem.

\section{ABSTRACT}

This article aims to analyze the meanings associated to the discussions about the processes of teacher training in the context of the First National Conference of Education promoted by the Brazilian Association of Education. This conference marked the beginning of a series of national meetings of the association that outlined a field of political, theoretical and institutional disputes. This event, which took place in 1927, had as its theme the primary education and generated an expressive documentation, highlighting the 113 theses presented. These and other documents of the Brazilian Association of Education compose the sources that support this analysis, which seeks to identify normative and antithetical concepts asymmetric present in the language game that structured the debates in the First National Conference of Education. The analysis of this language made possible the understanding of the place and the meaning of the teacher in the abeano discourse.

KEYWORDS: First National Conference on Education. Brazilian Association of Education. Teacher training. Asymmetric antithetic concepts. Language game.

\section{RESUMEN}

\section{FORMACIÓN DE PROFESORES EN LOS DEBATES DE LA I CONFERENCIA NACIONAL DE EDUCACIÓN (ICNE - 1927)}

Este artículo busca analizar los sentidos asociados a las discusiones sobre los procesos de formación de profesores en el contexto de la I Conferencia Nacional de Educación promovida por la Asociación Brasileña de Educación. Esta conferencia representó el inicio de una secuencia de encuentros nacionales de dicha asociación que delinearon un campo de disputas políticas, teóricas e institucionales. Este evento, ocurrido en 1927, tuvo como tema la enseñanza primaria y generó una expresiva documentación, con destaque para las 113 tesis presentadas. Estos y otros documentos de la Asociación Brasileña de Educación componen las fuentes que sostienen este análisis, que busca identificar conceptos normativos y antitéticos asimétricos presentes en el juego de lenguaje que estructuró los debates en la I Conferencia Nacional de Educación. El análisis de ese lenguaje posibilitó la comprensión del lugar y del significado del profesor en el discurso abeano.

PALABRAS CLAVE: I Conferencia Nacional de Educación. Asociación Brasileña de Educación. Formación de profesores. Conceptos antitéticos asimétricos. Juego de lenguaje. 


\section{INTRODUÇÃO}

Este artigo pretende analisar aspectos relacionados à Primeira Conferência Nacional de Educação (ICNE), organizada pela Associação Brasileira de Educação (ABE) e pela Inspetoria Geral da Educação do Paraná, realizada em 1927, na cidade de Curitiba. A ICNE foi a primeira conferência de um conjunto de 13 realizadas pela $A B E$ entre 1927 e 1967. Esse evento ocorreu em um momento de intensa discussão sobre as reformas educacionais que estavam sendo implementadas em diferentes estados brasileiros no primeiro quartel do século $X X^{1}$.

A ICNE, de maneira particular, e as CNEs, de maneira geral, representaram espaços de enunciação e debate sem precedentes na história da educação no Brasil, reunindo intelectuais, professores primários, normalistas, secundários e universitários, além de administradores públicos e jornalistas interessados no tema da educação nacional. Tema que ultrapassou os limites do horizonte pedagógico e das políticas de governos para se constituir como uma questão estratégica para a afirmação do Brasil como Estado sintonizado com o processo de modernização que impactava diferentes países da América e da Europa².

A I CNE teve como foco principal a organização do ensino primário. No cerne dessa questão estava a formação do professor normalista, considerado o personagem principal desse processo. É perceptível na análise da documentação a pressuposição de que o sucesso das reformas do ensino primário dependia do engajamento do professorado para a sua implementação. Em outros termos, segundo a visão dos

\footnotetext{
1 Em Santa Catarina esse processo reformista ocorreu no início da década de 1910, sendo Orestes Guimarães o seu mentor intelectual e administrativo. As reformas em São Paulo foram promovidas por Sampaio Dória (1920), no Distrito Federal foram conduzidas por Carneiro Leão e Fernando de Azevedo (1922 e 1928). Na Bahia (1924) e em Minas Gerais (1927), Anísio Teixeira e Francisco Campos, respectivamente, estiveram à frente desse ciclo reformista. As reformas no Ceará (1922), em Pernambuco (1928) e no Paraná (1920) foram, respectivamente, lideradas por Lourenço Filho, Carneiro Leão, César Prieto Martinez e Lysímaco Ferreira da Costa (VIEIRA; DANIEL, 2015).

2 Ao longo deste texto, utilizaremos o termo "intelectual" apoiados na problematização apresentada por Vieira (2011), na qual o autor descreveu e analisou as características que marcaram o comportamento público desse grupo social a partir de pesquisa sobre o campo educacional entre 1870 e 1960 . Nessa investigação o autor salientou quatro aspectos que balizam o seu entendimento do intelectual como ator coletivo da esfera pública: a) sentimento de pertencimento ao estrato social que, ao longo dos séculos XIX e XX, produziu a identidade social do intelectual; $b$ ) engajamento político propiciado pelo sentimento de missão ou dever social; c) elaboração e veiculação do discurso que estabelece a relação entre educação e modernidade; e d) assunção da centralidade do Estado como agente político para a efetivação do projeto moderno de reforma social.
}

Educação \& Formação, Fortaleza, v. 4, n. 10, p. 95-111, jan./abr. 2019

DOI: https://doi.org/10.25053/redufor.v4i10.391

http://seer.uece.br/redufor 
dirigentes da $A B E$, a expertise dos administradores públicos e a vontade política dos governos não valeriam de nada se os professores, entendidos como executores das reformas, não estivessem convencidos e preparados para torná-las realidade.

O professor, nesse contexto, seria o mediador entre as proposições apresentadas pelos intelectuais que ocupavam a administração do Estado e o público da escola, em particular, alunos e familiares. Confirma esse entendimento o fato de que as reformas estaduais implementadas, ou em vias de implementação no período, concentraram parte significativa das suas energias na ampliação e na reestruturação das Escolas Normais. O Paraná, nesse sentido,

[...] é exemplar, uma vez que as reformas mais gerais na organização do ensino público, iniciadas em 1920 pelo Inspetor Geral de Ensino, o paulista Prieto Martinez, ocorreram paralelamente à reorganização da Escola Normal, pela ação do seu diretor Lysímaco Ferreira da Costa [...]. Diante disso, podemos afirmar que, se até o início do século $X X$ as iniciativas para formação de professores apresentavam-se de maneira pontual e isolada, neste momento, passam a ser pensadas como estratégicas para a modernização do país. (VIEIRA; DANIEL, 2015, p. 48) ${ }^{3}$.

As fontes utilizadas neste artigo referem-se a documentos relacionados à $A B E \mathrm{e}$ à ICNE. Entre estes, destacamos: Estatuto da $\mathrm{ABE}$; ata da sessão de instalação da ICNE; sessão preparatória da ICNE; relatório das sessões; relatório da comissão organizadora da ICNE; e sobretudo as 113 teses apresentadas durante o evento.

Em termos metodológicos, operaremos a partir de inspirações associadas à história intelectual, particularmente os pressupostos teóricos que enfatizam a análise da linguagem, na perspectiva de identificar, especialmente no âmbito das conclusões deste estudo, o conjunto de conceitos normativos que estrutura o modo de falar sobre educação nesse evento. Esse tipo de abordagem tem como referência principal a história dos conceitos e a obra de Reinhard Koselleck.

Para Koselleck (2006, p. 109), "[...] os conceitos são, portanto, vocábulos nos quais se concentra uma multiplicidade de significados [...]. Um conceito pode ser claro, mas deve ser polissêmico". Os conceitos são termos plásticos e que transcendem aos seus contextos originais de enunciação, projetando-se no tempo e no espaço. Os conceitos são registros da realidade, indicadores de mudanças na vida social, mas

3 A Escola Normal de Curitiba foi fundada em 1876, sendo, no início dos anos de 1920, a única Escola Normal no Paraná. Nas duas administrações consecutivas de Caetano Munhoz da Rocha (1920-1928), foram criadas as Escolas Normais de Ponta Grossa e de Paranaguá.

Educação \& Formação, Fortaleza, v. 4, n. 10, p. 95-111, jan./abr. 2019

DOI: https://doi.org/10.25053/redufor.v4i10.391

http://seer.uece.br/redufor 
também fatores de transformação da própria realidade. Nos termos postos por Koselleck (2006), os conceitos fundamentais para a estruturação do debate político têm uma dupla dimensão: eles refletem o espaço de experiência, a realidade daqueles que o enunciam, e também os horizontes de expectativa, ou seja, aquilo que os seus enunciadores projetam como possibilidade de futuro. Os conceitos podem ser identificados a partir de duas perspectivas: a semasiológica, considerando as palavras e os seus significados, e a onomasiológica, quando um mesmo significado está presente em diferentes palavras. Nessa operação, cabe ao investigador identificar os conceitos análogos ou correlatos e os opostos ou antitéticos que participam da formação de um jogo de linguagem 4 .

A história dos conceitos permite estudar os termos fundamentais presentes na linguagem que funcionam como elementos estruturantes dos argumentos que produzem a legitimação das práticas sociais. Nesse sentido, o estudo da linguagem e dos conceitos não se apresenta como reflexão abstrata, tal como se procede no campo da lógica, uma vez que a história dos conceitos pressupõe uma relação tensional e permanente entre linguagem e realidade, uma vez que "[...] os acontecimentos históricos e a sua constituição linguística estão entrelaçados" (KOSELLECK, 2006, p. 236).

\section{ABE E ICNE: PRODUZINDO UM PÚLPITO AUTORIZADO}

Nos anos de 1920, o Brasil viveu a emergência de novos atores, com novas ideias e projetos políticos. Esse período - de crise na República - envolveu inovações técnicas, urbanização e produção cultural, despertando grande interesse dos historiadores e cientistas sociais. Segundo Milton Lahuerta (1997, p. 93):

[...] justamente nos anos 20 que a decepção quanto à possibilidade de a República realizar o ideal de uma sociedade nova torna-se absolutamente explosiva. Particularmente para os intelectuais, a década de 1920 será de questionamentos inéditos, até então, e que permanecem em pauta pelas

4 Koselleck (2006) privilegiou nos seus escritos a categoria campo semântico, contudo, neste artigo, pensamos esta categoria como um equivalente heurístico do conceito de jogo de linguagem. $O$ jogo de linguagem tem como pressuposto as ideias de Wittgenstein, que entende o jogo de linguagem como expressão da conversação que ocorre no interior de contextos sociais delimitados, restritos a um número determinado de falantes que compartilham um léxico e regras tacitamente estabelecidas para a enunciação.

Educação \& Formação, Fortaleza, v. 4, n. 10, p. 95-111, jan./abr. 2019

DOI: https://doi.org/10.25053/redufor.v4i10.391

http://seer.uece.br/redufor 
próximas décadas. Não apenas concepções tradicionais são atacadas, mas também as instituições republicanas - identificadas com uma legalidade que não tem correspondência no real - elevando o pathos de ruptura, trazendo à tona novos atores e a problemática dos direitos e da participação.

Para Vieira (2007), a década de 1920 é um marco na historiografia por encerrar um cenário de intensas contradições e mudanças. O final da Primeira Guerra, o acirramento da competição pelos mercados mundiais, o incremento nas técnicas de produção industrial e os adventos do primeiro país socialista e do movimento fascista na Europa foram aspectos que marcaram, em grande medida, o período, estudado sob os signos da modernidade, do modernismo e da modernização, entendidos como representações, projetos e práticas sociais vinculados aos desejos de mudança e de progresso que - em maior ou em menor profundidade, em maior ou em menor velocidade - marcaram as experiências de diferentes países. Enquanto o modernismo conotou movimentos estéticos, a modernização representou medidas de racionalização da vida social e da esfera econômica. O termo "modernidade" tem uma polissemia mais ampla, pois conotou um período histórico associado ao télos do progresso e ao poder da razão. O ethos moderno construiu seus sentidos mais profundos apontando para o dever-ser, para a construção de uma nova forma de civilidade.

Desde o final do século XIX até as primeiras décadas do século XX, no Brasil, a crença na ignorância do povo e na necessidade de afirmação de uma identidade e de uma consciência nacional levaram os intelectuais a defender o projeto de modernizar o país, assim a educação foi considerada como um investimento decisivo. Nesse cenário, um grupo de intelectuais, formado por médicos, engenheiros, advogados e professores, fundou em 1924, na cidade do Rio de Janeiro, a ABE. Para Carvalho (1998, p. 31):

[...] a $A B E$ teria sido um dos instrumentos mais eficazes de difusão do pensamento pedagógico europeu e norte-americano e um dos mais importantes, senão o maior, centros de coordenação e de debate para o estudo e soluções de problemas educacionais [...]. Em especial, as Conferências Nacionais, promovidas pela associação, aproximando educadores de todos os Estados e congregando-os em diferentes centros do país. 
A ABE, em seu estatuto, no artigo 1ํ, afirmava: "[...] a Associação Brasileira de Educação tem por fim promover no Brasil a difusão e o aperfeiçoamento da educação, em todos os seus ramos, estimulando as iniciativas que possam mais eficazmente atingir estes objetivos" (ABE, 1925, Estatuto).

Nos três primeiros anos de existência da $A B E$, os seus debates ficaram restritos a pequenos círculos, limitando-se principalmente aos intelectuais que a compunham. Porém, a partir de 1927, essa entidade procurou dar maior visibilidade e abrangência para suas ideias e projetos, quando passou a promover conferências em âmbito nacional. A ata da reunião preparatória da I CNE revela esse objetivo:

Prosseguindo na execução de seu programa educacional, resolve a Associação Brasileira de Educação realizar, em todos os Estados do Brasil, conferências nacionais de educação com a participação de todas as unidades federativas, visando à congregação de todos os professores brasileiros em torno dos mais elevados ideais de civismo e de moral. Combate-se, destarte, o espírito separatista que por vezes se revela aqui, ou ali, trabalhando-se nobremente pela unidade nacional. (ABE, 1927, Atas).

A ICNE, iniciada estrategicamente no dia 19 de dezembro, marcou as comemorações da emancipação política da província do Paraná, ocasião em que a imprensa paranaense deu grande relevo ao momento da sua instalação, bem como em relação aos seus resultados. As autoridades presentes na sessão de abertura também evidenciaram a importância dada ao momento, uma vez que compuseram a mesa: Caetano Munhoz da Rocha, presidente do estado do Paraná e representante do presidente de honra do congresso; Washington Luís, então presidente da república; dom João Braga, arcebispo metropolitano de Curitiba; desembargador Clotário Portugal, secretário-geral do estado; e doutor João Moreira Garcez, prefeito municipal de Curitiba. Além das autoridades, segundo a ata da ABE, "[...] achavam-se presentes para mais de quatrocentos congressistas, de trezentos alunos da escola normal secundária e cerca de duas mil pessoas, apresentando o Teatro Guaíra um aspecto imponente" (ICNE, 1927, Ata da Sessão de Instalação). No seu discurso, Caetano Munhoz da Rocha "[...] agradeceu aos governos dos Estados, aos delegados da ABE e ao do governo da República, o seu precioso concurso à majestosa obra do fortalecimento da unidade nacional pela educação do povo" (ICNE, 1927, Ata da Sessão de Instalação). Os bordões da unidade nacional e da educação do povo, reiterados pelo presidente do 
estado do Paraná, reforçavam sentidos compartilhados pelos participantes do evento, repetidos regularmente nas teses apresentadas à conferência ${ }^{5}$.

Carvalho (1998) afirma que a campanha cívico-educacional promovida pela ABE combinou dois projetos nacionalistas: um deles, católico, enfatizava o papel das elites intelectuais na construção de um nacionalismo que valorizava as tradições e a moral católica; e o outro entendia que a escola republicana deveria ser laica, contudo convergia com os católicos, tanto no que diz respeito ao papel condutor das elites intelectuais como na imperiosidade de formação da consciência nacional a partir da escola primária.

Dos 17 delegados que representaram oficialmente estados brasileiros, somente o Rio de Janeiro se fez representar por uma mulher. Participariam da ICNE:

\begin{abstract}
a) Os representantes dos Estados e do Distrito Federal; b) O presidente e delegados da Associação Brasileira de Educação; c) Os professores públicos e particulares dos cursos superiores, secundários ou profissionais do país e as pessoas cultas que aderiram a esta nobre iniciativa; d) Os diretores e os professores da Universidade do Paraná, dos ginásios, escolas normais, escolas profissionais complementares, grupos escolares, escolas primárias públicas e particulares, colégios, etc., do Estado do Paraná. (ABE, 1927, Ata).
\end{abstract}

A ICNE contou com oito comissões temáticas: duas de ensino primário; uma de ensino secundário; três de temas gerais; uma de educação higiênica; e uma de ensino superior. Foram discutidas 113 teses, sendo que quatro delas foram apresentadas em nome da direção da ABE. As teses propostas foram as seguintes:

\begin{abstract}
1ㅇ - a unidade nacional: a) pela cultura literária; b) pela cultura cívica; c) pela cultura moral; $2^{\circ}$ - a uniformização do ensino primário, nas suas ideias capitais, mantida a liberdade de programas; $3^{\circ}$ - a criação de escolas normais superiores em diferentes pontos do país para preparo pedagógico; $4^{\circ}$ - a organização dos quadros nacionais, corporações de aperfeiçoamento técnico, científico e literário. (ABE, 1927, Ata).
\end{abstract}

Vieira e Bona Júnior (2007, p. 14-15) destacaram que a fundação da ABE e a organização da ICNE revelam o intento dos intelectuais vinculados à associação de estruturação de um púlpito de enunciação autorizado, capaz de:

${ }^{5}$ Um dos aspectos que justificava a ideia da unidade nacional, na década de 1920, está relacionado à questão da imigração e, sobretudo, da existência de escolas de imigrantes, que ministravam seus conteúdos na língua dos novos colonos. Muitas teses apresentadas na ICNE discutem essa questão e sinalizam para o perigo de desagregação do país em função da multiplicidade de culturas e línguas que, segundo esses congressistas, não se integravam à cultura e à língua nacional.

Educação \& Formação, Fortaleza, v. 4, n. 10, p. 95-111, jan./abr. 2019

DOI: https://doi.org/10.25053/redufor.v4i10.391

http://seer.uece.br/redufor 
[...] dar visibilidade às ações do estado; legitimar os intelectuais envolvidos com a direção das reformas; conquistar o consentimento dos professores, pais e alunos para a implantação das mudanças pretendidas; e, por fim, afirmar o discurso da modernidade que associava os investimentos em educação às ideias de progresso, desenvolvimento e bem-estar social.

As divergências e as disputas no interior da $A B E$ e da ICNE são percebidas especialmente em relação ao problema do ensino religioso no interior da escola pública. Não obstante, essas tensões não foram suficientes para provocar cisões na associação, tal como ocorrera em meados dos anos de 1930. Sendo assim, é possível falarmos de um discurso abeano que, a partir da produção dos púlpitos autorizados das CNEs, pretendia disseminar significantes e significados associados ao tema da educação. Logo, no grupo dirigente da entidade dos anos de 1920, verificamos uma grande convergência, tanto na dimensão da percepção do espaço de experiência como na projeção dos horizontes de expectativas. Em outros termos, o diagnóstico dos problemas, assim como as suas pretensas soluções, eram amplamente compartilhados pela intelectualidade que fundou a $A B E$ e organizou a ICNE.

\section{HIERARQUIZANDO PRIORIDADES E TRAÇANDO ESTRATÉGIAS: A QUESTÃO DA FORMAÇÃO DE PROFESSORES}

A formação dos professores não foi incluída como um tema específico nas 13 CNEs (1927-1967), contudo podemos afirmar que essa questão perpassou as discussões, em maior ou em menor medida, ao longo de todas as conferências ${ }^{6}$. $\mathrm{Na}$ ICNE esse ponto foi regularmente mencionado, particularmente associado à discussão sobre a organização da escola primária, tema principal do evento. No que tange ao ensino primário, o sentido que perpassou as manifestações, tanto de congressistas sem notoriedade como de intelectuais ilustres, foi o da padronização dos seus programas e dos seus métodos de ensino. A crença compartilhada, por obscuros e notórios, era da necessidade de se produzir a unidade nacional a partir do ensino primário, considerado como base de formação da população escolar. A estratégia para alcançar essa uniformização do ensino, considerando a dimensão e a diversidade

6 Para um estudo sobre o discurso educacional enunciado ao longo das 13 Conferências Nacionais de Educação (1927-1967), ver Vieira (2017a).

Educação \& Formação, Fortaleza, v. 4, n. 10, p. 95-111, jan./abr. 2019

DOI: https://doi.org/10.25053/redufor.v4i10.391

http://seer.uece.br/redufor 
cultural do país, seria padronizar os processos de formação dos professores. Esse cálculo precário e pretensioso pressupunha que, padronizados os procedimentos docentes, se uniformizariam os processos formativos.

Essa estratégia ganhou sentido na proposição de criação das Escolas Normais Superiores. Nesse sentido, entre as quatro teses apresentadas pela Diretoria da ABE, já mencionadas anteriormente, a primeira delas defendia a unidade nacional, a segunda propunha a uniformização do ensino primário e a terceira versava sobre a criação das Escolas Normais Superiores. Esse tipo de instituição, com caráter público e de responsabilidade do governo federal, deveria ser instalada em lugares estratégicos do país.

As teses da diretoria, em grande medida, balizaram e orientaram o debate. Assim, Ferdinando Laboriau (ICNE, Tese 45), representando a ABE, afirmava que "[...] a base da educação nacional tem que ser a instrução primária", e esta deveria estar alicerçada sobre a boa formação dos professores. Para que a educação primária

[...] tenha uma diretriz sistematizada, é indispensável uma atividade muito diferente da simples subvenção de escolas estaduais ou municipais pela União, como se estabelece na atual Lei Federal do Ensino (Decreto n. 16.782-A, de 13 de janeiro de 1925). É preciso começar pelo princípio, cuidando das Escolas Normais Superiores, para constituir um corpo selecionado de professores das Escolas Normais e Secundárias. (ICNE, Tese 45).

Barbosa de Oliveira, presidente da ABE durante a ICNE, em tese intitulada "A criação das Escolas Normais Superiores, em diferentes pontos do país, para preparo pedagógico", afirmava que a

[...] escola, no conceito hodierno, não é um simples instrumento de instrução; tem uma finalidade superior, que é a de preparar o aluno para a vida, desenvolvendo- Ihe as faculdades físicas, morais e intelectuais, conjunto criador da sua própria individualidade. Esse tríplice aspecto da educação deve ser ministrado largamente ao povo, para fazer de cada indivíduo um elemento útil à sociedade e à pátria. (ICNE, 1927, Tese 85).

Para a escola ser útil à pátria, de acordo com Barbosa de Oliveira, seria necessário concentrar os investimentos no professor, prepará-lo adequadamente, já que muito "[...] importa o método de ensino, mas muito mais importante é a qualidade do mestre" (ICNE, 1927, Tese 85). Dessa forma, o professor era visto como "[...] a alma do ensino" e a sua formação seria "[...] o ponto primordial de todo o problema educativo" (ICNE, 1927, Tese 85).

Educação \& Formação, Fortaleza, v. 4, n. 10, p. 95-111, jan./abr. 2019

DOI: https://doi.org/10.25053/redufor.v4i10.391

http://seer.uece.br/redufor 
Para a congressista Myriam de Souza, o agente principal seria:

[...] aquele que personifica a instrução, é o professor; e, por isso mesmo, ele deve compenetrar-se dos seus deveres. Deve tomar ao seu encargo os pequeninos brasileiros e, mais tarde, entregá-los à Pátria como cidadãos fortes, unidos, aperfeiçoados os espíritos, educados no bem, formados os caracteres para a glória do nome de brasileiros. Para tão grande obra, é mister que se preparem convenientemente os professores e que sejam estes escolhidos pelas suas aptidões e amor ao ensino, porque assim como o bom professor é o melhor guia da mocidade também o mau é degenerador da infância. (ICNE, 1927, Tese 38).

Reforçando esse argumento, Nestor Mendes, defendendo o ensino da moral e do civismo, argumentava que:

Sem um professorado constituído de verdadeiros caracteres, de abnegados sacerdotes, de patriotas sinceros, é inútil qualquer tentativa. A seleção não deve atender unicamente às competências, ao valor intelectual; antes, deve constituir a guarda avançada os que têm caráter, os que não são venais, os que não prevaricam e não se curvam senão diante da verdade. [...]. Deve ter (o professor) hábitos de pontualidade, asseio, ordem, disciplina, urbanidade e caridade. Desde o primeiro instante, com paciência, carinho e bondade, deve corrigir nos seus alunos todos os seus maus costumes aparentes, lembrando-se sempre dos defeitos da própria educação doméstica. Tudo isso deverá fazer com observação profunda e tino especial. (ICNE, 1927, Tese 87).

Para Mendes, o professor, através do seu exemplo, deve ter por objetivo ensinar os alunos condutas virtuosas e honestas:

[...] criar hábitos de trabalho honesto, da prática das virtudes, de respeito mútuo e de altruísmo, mas com a condição fundamental de se erigir em um exemplo vivo desses predicados, para que a sugestão dos seus atos lembre a todo instante às crianças os ensinamentos que doutrinou. Todo o ensino da moral que não tiver por base este lema é inútil, podendo ser até pernicioso. (ICNE, 1927, Tese 87).

Roberto Emílio Mongruel, da Escola Normal Primária de Ponta Grossa, argumentava sobre o dever do professor:

Deve o professor servir de exemplo a seus alunos nos menores atos de sua vida, quer pública, quer privada. $\mathrm{Na}$ escola deve ser o primeiro a chegar e o último a sair, guardando sempre modelar postura, quer no trajar, como nos gestos e nas expressões, desempenhando a sua obrigação com a máxima ordem, cada coisa a seu tempo e lugar. Assim procedendo, alcança o professor a sua autoridade moral, que é a base, por assim dizer, de toda disciplina, conquistando o ascendente sobre os seus alunos, despertando-lhes o afeto e carinho, para o que necessita dispensar-Ihes o mesmo sentimento, tratando-os afetuosamente e dando mostra de acendrado carinho, impondo-se pela persuasão e pela delicadeza. (ICNE, 1927, Tese 37).

Educação \& Formação, Fortaleza, v. 4, n. 10, p. 95-111, jan./abr. 2019

DOI: https://doi.org/10.25053/redufor.v4i10.391

http://seer.uece.br/redufor 
Palmyra Bompeixe de Mello reforçava esse argumento da educação pela exemplaridade: "O exemplo é a melhor escola, portanto o professor que não tiver uma sólida Educação Moral não poderá formar o caráter [...]. O educador deve ter o seu caráter bem formado, porque deste depende o valor dos indivíduos" (ICNE, 1927, Tese 89).

Como podemos notar, as manifestações dos congressistas - considerando os dirigentes da $A B E$, intelectuais reconhecidos e/ou professores participantes do evento - atribuíam ao corpo docente um papel central no projeto de reforma da educação nacional, representando esse profissional como uma espécie de herói prometeico, que instruiria as crianças e, por extensão, levaria o país à modernidade. A ênfase dos discursos recaía muito mais sobre a formação moral e cívica do professor do que sobre sua preparação intelectual e pedagógica. Pouco se falava também sobre a sua profissionalização, considerando salários, condições de trabalho e de tempo dedicado à formação. Dessa forma, entendemos que as proposições em debate na ICNE não promoviam a valorização profissional dos docentes, uma vez que não enfrentavam efetivamente os problemas do professorado, tais como a falta de infraestrutura, as longas jornadas de trabalho e a insuficiente remuneração.

Para dissimular essa descompensação entre as exigências que eram feitas ao magistério (laboriosidade, moralidade, civismo, responsabilidade, inteligência e racionalidade) e as condições oferecidas para a prática da docência nas escolas, verificamos o uso reiterado de termos como "sacerdócio", "missão", "abnegação", "amor às crianças" e "desprendimento". O uso dessas palavras sugere o exercício do magistério como uma espécie de sacrifício ou tributo que os professores realizariam em favor do projeto da nação. Nesse período, a feminização do magistério primário era uma realidade estrutural da profissão, de modo que podemos afirmar que esses sacrifícios recairiam principalmente sobre a mulher professora.

Duas teses, apresentadas por homens, exemplificam essas imposições sobre a vida da mulher professora. "O celibato pedagógico feminino" é o título da tese que sustentou que a professora não deveria/poderia unir-se em matrimônio, já que o casamento e os filhos desviariam sua atenção e energias dos seus alunos, considerados pelo congressista como os filhos que a professora deveria adotar (ICNE, 1927, Tese 68). A segunda tese, sintonizada com essa disposição de exigir renúncias 
da mulher professora, foi apresentada pelo médico e dirigente da ABE Fernando de Magalhães, intitulada "Para lutar contra o analfabetismo: o serviço pedagógico obrigatório, dever cívico feminino decorrente do direito de voto às mulheres". O enunciado do título é muito preciso e já antecipa o teor do argumento. Na sua introdução, Magalhães afirmava ser favorável ao voto feminino, que ainda não era um direito consagrado no Brasil na década de 1920, contudo ponderava: "[...] sou favorável por polidez - as mulheres desejam-no, faça-se-Ihes a vontade" (ICNE, 1927, Tese 53). O chamado Serviço Pedagógico Obrigatório equivaleria ao serviço militar, previsto para os homens, e recairia sobre as mulheres que se cadastrassem como eleitoras. $O$ serviço compulsório e não remunerado teria como escopo alfabetizar as crianças da cidade na qual a eleitora residisse por um período de dois anos.

\section{4 À GUISA DE CONCLUSÃO: JOGO DE LINGUAGEM, CONCEITOS NORMATIVOS E ANTITÉTICOS ASSIMÉTRICOS}

Neste espaço de conclusões, vamos nos concentrar em traçar algumas hipóteses para pensarmos a ICNE como um espaço público no qual se praticava um jogo de linguagem, com atores linguísticos, léxicos e significados compartilhados. Nesse jogo, determinados conceitos normativos estruturaram os principais significados que perpassaram os debates no evento.

Sendo assim, a primeira questão que salientaremos está relacionada ao que Koselleck (2006) denomina de conceitos antitéticos assimétricos. Para Koselleck (2006), esses conceitos formam pares binários, tais como heleno-bárbaro ou cristão-pagão. 0 que caracteriza esses pares antitéticos assimétricos "[...] é que eles determinam uma posição seguindo critérios tais que a posição adversária deles resultante só pode ser recusada. Nisto reside sua eficácia política" (KOSELLECK, 2006, p. 195). Em outros termos, o primeiro termo do par tem para os seus enunciadores um significado positivo, enquanto que o segundo é marcadamente negativo. A historicidade da linguagem supõe a variação semântica, logo entender o significado negativo ou positivo de um termo depende da compreensão dos sentidos que as palavras assumem no contexto dos diferentes jogos de linguagem. 
Desse modo, analisando o jogo de linguagem praticado na ICNE, identificamos o uso regular de conceitos antitéticos assimétricos. Dois exemplos-chave para entender o discurso abeano são: o par unidade-desagregação, mobilizado nos argumentos sobre a formação da nação, da consciência e da identidade nacional; ou ainda o par instrução-ignorância, presente regularmente nos debates sobre a expansão da escolaridade ou, de forma particular, na discussão sobre a obrigatoriedade do ensino primário. $O$ uso desses conceitos binários na conversação pública é típico do debate político, que visa à exclusão, à impugnação, ao silenciamento e à derrota completa do adversário. Ao adversário, identificado como a representação do segundo termo do par, é imputada uma posição impossível de ser assumida, já que defender a desagregação do país ou a ignorância do povo não era uma opção válida nas disputas em curso no período. Dessa maneira, fazendo uso dessa estratégia retórica, a intelectualidade que liderava o projeto abeano não encontrava resistências, uma vez que se produziu o sentido da identificação entre a $A B E$, suas ações e projetos e a defesa da unidade nacional e da instrução do povo.

Em contraste com o debate científico, que busca presumidamente a verdade, 0 debate político visa derrotar os seus adversários e conquistar o consentimento da sociedade para poder governar. Nesses termos, a ICNE não se caracterizou como um espaço de debate para se encontrar a verdade, mas sim impor uma maneira de pensar. A construção do púlpito (ABE-CNEs), a enunciação autorizada dos intelectuais ilustres e o uso de conceitos binários (antitéticos assimétricos) foram decisivos para desmobilizar ou desqualificar qualquer adversário, sejam estes do campo político ou educacional.

$\mathrm{Na}$ análise que realizamos, outros pares de conceitos antitéticos assimétricos podem ser identificados, incluindo também os seus termos correlatos, que funcionam retoricamente para reforçar determinados significados, seja da positividade do primeiro termo do par ou da negatividade do segundo. 
Quadro 1 - Conceitos antitéticos assimétricos presentes na linguagem mobilizada nos debates da ICNE: Curitiba-1927

\begin{tabular}{|c|c|}
\hline Conceitos correlatos & Antíteses assimétricas correlatas \\
\hline Unidade nacional & Desagregação \\
\hline Integração nacional & Separatismo \\
\hline Caráter nacional & Anarquismo \\
\hline Consciência nacional & Divisão \\
\hline Território nacional & Fragmentação \\
\hline Nação & Dissolução \\
\hline Estado & Ruína \\
\hline Civilização & Barbárie \\
\hline Cultura & Ignorância \\
\hline Instrução & Analfabetismo \\
\hline Educação & Selvageria \\
\hline Laboriosidade & Indolência \\
\hline Disciplina & Ociosidade \\
\hline Ordem & Desordem \\
\hline Obediência & Desobediência \\
\hline Responsabilidade & Irresponsabilidade \\
\hline Saúde & Doença \\
\hline Higiene & Degeneração \\
\hline Eugenia & Patologia \\
\hline Saneamento & Distúrbio \\
\hline Asseio & Verminose \\
\hline Profilaxia & Sífilis \\
\hline Puericultura & Alcoolismo \\
\hline Moderno & Tradicional \\
\hline Modernidade & Atraso \\
\hline Modernização & Arcaico \\
\hline Progresso & Antiquado \\
\hline Desenvolvimento & Anacrônico \\
\hline Raça & Caboclo \\
\hline Povo & Jeca \\
\hline & Colono \\
\hline & Matuto \\
\hline & Imigrante \\
\hline Urbano & Rural \\
\hline Cidade & Sertão \\
\hline Verdadeiro & Falso \\
\hline Racional & Irracional \\
\hline Método & Improviso \\
\hline Conhecimento & Ignorância \\
\hline Ciência & Superstição \\
\hline
\end{tabular}

Fonte: Quadro elaborado pelos pesquisadores (2018).

Um outro grupo de conceitos normativos presente na linguagem mobilizada e compartilhada na ICNE assume essa característica dos conceitos antitéticos assimétricos, embora o segundo termo do par não seja sequer enunciado nas falas dos congressistas. São exemplos desse fenômeno os conceitos correlatos "civismo" e "patriotismo". Talvez, nesse caso, a positividade desses significantes e significados 
estivesse tão naturalizada no jogo de linguagem praticado que não exigia a enunciação do termo oposto desigual.

Em relação aos professores, assim como demonstramos ao longo desta análise, prevaleceu a noção da sua centralidade em todo esse processo de afirmação do projeto educacional da $A B E$, ainda que esse protagonismo almejado pelo discurso abeano não estivesse sustentado em políticas claras de valorização e profissionalização do magistério. Logo, a busca do convencimento e do consentimento do magistério para a implementação de reformas e ações educativas sustentou-se sobretudo na mobilização de termos e significados próprios do léxico do discurso religioso, tais como "missão", "sacerdócio", "sagrado", "crença", "amor", "vocação" e "abnegação".

As principais conclusões a que chegamos sobre a ICNE foram as seguintes: 1) o evento funcionou como um púlpito de ostentação dos projetos e das ações da $\mathrm{ABE}$, dos intelectuais que a dirigiam e do estado do Paraná, que acolheu e patrocinou o evento; 2) a linguagem presente nos debates na ICNE caracterizou-se pelo uso de conceitos binários, antitético-assimétricos, que não favoreceram a discussão aberta e racional dos temas, prevalecendo o tom emocional e grandiloquente; 3) o jogo de linguagem praticado na ICNE assemelha-se às regras da conversação no campo político, uma vez que o debate não buscava a verdade, mas sim a imposição de uma visão nacionalista e autoritária; 4) por fim, no que tange ao professorado, esse jogo de linguagem disseminou o sentido da ação profissional como um tributo à nação, eivada de sacrifícios, responsabilidades e sobretudo sem uma perspectiva definida de formação intelectual e pedagógica.

\section{REFERÊNCIAS}

BONA JÚNIOR, A. Educação e modernidade nas conferências educacionais da década de 1920 no Paraná. 2005. Dissertação (Mestrado em Educação) - Programa de Pós-Graduação em Educação, Universidade Federal do Paraná, Curitiba, 2005.

BONA JÚNIOR, A.; VIEIRA, C. E. O discurso da modernidade nas conferências educacionais na década de 1920 no Paraná. In: VIEIRA, C. E. (Org.). Intelectuais, educação e modernidade no Paraná (1886-1964). Curitiba: UFPR, 2007. p. 13-40.

CARVALHO, M. M. C. Molde nacional e fôrma cívica: higiene, moral e trabalho no projeto da Associação Brasileira de Educação (1924-1931). Bragança Paulista: USF, 1998. 
FARIA, M. C. N. Primeira Conferência Nacional de Educação: intelectuais, educação e modernidade (Curitiba - 1927). 2017. 60 f. Trabalho de Conclusão de Curso (Graduação em Pedagogia) - Programa de Graduação em Pedagogia, Universidade Federal do Paraná, Curitiba, 2017.

HOELLER, S. A. O. As conferências educacionais: projetos para a nação e modernização pedagógica nos anos de 1920 - Brasil. 2014. 480 f. Tese (Doutorado em Educação) - Programa de Pós-Graduação em Educação, Universidade Federal de Santa Catarina, Florianópolis, 2014.

KOSELLECK, R. Futuro passado: contribuição à semântica dos tempos históricos. Rio de Janeiro: Contraponto: PUC, 2006.

LAHUERTA, M. Os intelectuais e os anos 20: moderno, modernista e modernização. In: LORENZO, H. C.; COSTA, W. P. (Org.). A década de 1920 e as origens do Brasil moderno. São Paulo: Unesp, 1997. p. 93-114.

VALÉRIO, T. F. Associação Brasileira de Educação: as Conferências Nacionais de Educação como estratégias de intervenção da intelectualidade abeana na política educacional do ensino secundário no Brasil (1928-1942). 2013. 267 f. Tese (Doutorado em Educação) - Programa de Pós-Graduação em Educação, Universidade Federal do Paraná, Curitiba, 2013.

VIEIRA, C. E. Conferências Nacionais de Educação: intelectuais, Estado e discurso educacional (1927-1967). Educar em Revista, Curitiba, n. 65, p. 19-34, 2017 a.

VIEIRA, C. E. Contextualismo linguístico: contexto histórico, pressupostos teóricos e contribuições para a escrita da história da educação. Revista Brasileira de História da Educação, Maringá, v. 17, p. 31-55, 2017b.

VIEIRA, C. E. Erasmo Pilotto: identidade, engajamento político e crença dos intelectuais vinculados ao campo educacional no Brasil. In: LEITE, J. L.; ALVES, C. (Org.). Intelectuais e História da Educação no Brasil: poder, cultura e política. Vitória: UFES, 2011. p. 25-54.

VIEIRA, C. E. Intelectuais e o discurso da modernidade na I Conferência Nacional de Educação (Curitiba - 1927). In: BENCOSTTA, M. L. A. Culturas escolares, saberes e práticas educativas: itinerário histórico. São Paulo: Cortez, 2007a. p. 379-400.

VIEIRA, C. E. Jornal Diário como fonte e como tema para a pesquisa em História da Educação: um estudo da relação entre intelectuais, educação e modernidade. In: OLIVEIRA, M. A. T. (Org.). Cinco estudos em História e Historiografia da Educação. Belo Horizonte: Autêntica, 2007b. p. 11-40.

VIEIRA, C. E.; DANIEL, L. S. Lysímaco Ferreira da Costa e a formação de professores no Paraná na década de 1920. In: VIEIRA, C. E.; OSININSKI, D.; BENCOSTTA, M. L. (Org.). Intelectuais, modernidade e formação de professores no Paraná: 1910-1980. Curitiba: UFPR, 2015. p. 45-76.

Educação \& Formação, Fortaleza, v. 4, n. 10, p. 95-111, jan./abr. 2019

DOI: https://doi.org/10.25053/redufor.v4i10.391

http://seer.uece.br/redufor 


\section{FONTES}

Anais da I Conferência Nacional de Educação (I CNE)

Ata da sessão de instalação da ICNE

Estatuto da ABE

Relação dos estados participantes

Relatório da comissão organizadora da ICNE

Relatório das sessões

Sessão preparatória da ICNE

Teses apresentadas durante a ICNE

Carlos Eduardo Vieira (Brasil, Paraná, Curitiba) - Universidade Federal do Paraná (UFPR)

Pós-Doutor em Educação pela Universidade de Stanford e em História pela Universidade de Cambridge. Professor titular de História da Educação na UFPR. Presidente da Sociedade Brasileira de História da Educação (SBHE) e pesquisador do Conselho Nacional de Desenvolvimento Científico e Tecnológico (CNPq). Lidera o diretório do CNPq História da Educação: Instituições, Intelectuais e Culturas Escolares no Paraná e coordena os seguintes grupos de pesquisa: Grupo de Pesquisa História Intelectual e Educação (GPHIE) e Núcleo de Estudos e Pesquisas História, Educação e Modernidade (Nephem).

Lattes: <http://lattes.cnpq.br/3846360539727867>.

E-mail: <cevieira9@gmail.com>.

Maria Cristiane Nunes de Faria (Brasil, Paraná, Curitiba) - Universidade Federal do Paraná (UFPR) Graduada em Pedagogia pela UFPR. Integrante do Grupo de Pesquisa História Intelectual e Educação (GPHIE).

Lattes: <http://lattes.cnpq.br/5083363645993679>.

E-mail: <lia.mcnfaria@hotmail.com>.

Recebido em 1을 de outubro de 2018.

Aceito em 31 de dezembro de 2018.

Educação \& Formação, Fortaleza, v. 4, n. 10, p. 95-111, jan./abr. 2019

DOI: https://doi.org/10.25053/redufor.v4i10.391

http://seer.uece.br/redufor 